lations of Ufford ${ }^{8}$ and exp rimental data concerning the $\mathrm{CN}$ radical ${ }^{1}$. The discrepancy with the recent observations of Shenstone $\theta^{\theta}$ will be dealt with in a future communication. It is in no sense responsible for the discrepancy between our conclusions and those of Springall ${ }^{10}$ concerning the heat of atomization of carbon, this being due to entirely different reasons which are discussed in a forthcoming paper.

In conclusion, it seems to me that the expression 'mean bond-energy term' is an unfortunate choice. As originally employed for polyatomic molecules by Butler and Polanyi11, a constancy in energy is assumed for any one kind of link from molecule to molecule, differences in the dissociation energies being attributed entirely to resonance energy of the resulting radicals. This point of view ignores changes in the energy of unruptured links during a dissociation process, whereas the statement that bond-energies according to Skinner and Springall's usage $(a)$ show "a remarkable degree of constancy" seems difficult to maintain in the face of much experimental evidence. If this were so, then every process of the type

$$
\mathrm{CH}_{4}+\mathrm{CO}_{2} \rightarrow 2 \mathrm{H}_{2} \mathrm{CO} \text {, }
$$

in which the number of each type of bond remains the same, would be thermoneutral, whereas this is far from bəing the case. The example quoted is endothermic to the extent of about $60 \mathrm{kcal}$., which must be attributed to changes in the energies of the $\mathrm{C}-\mathrm{H}$ or $\mathrm{C}=\mathrm{O}$ bonds or, more probably, both. The extent to which the bond-energies (as distinct from the dissociation energies) of $\mathrm{C}-\mathrm{H}, \mathrm{C}=\mathrm{O}$ and many other bonds do, in fact, vary has received frequent consideration in the literature ${ }^{12}$.

University College,

L. H. LonG Exeter.

${ }^{1}$ Long, L. H., and Norrish, R. G. W., Proc. Roy. Soc., A, 18., 337 (1946).

"Pauling, L., "The Nature of the Chemical Bond", $47 \mathrm{ff}$. (Cornell Univ. Press, New York. 2nd Ed., 1945).

${ }^{3}$ See, for example, Coulson, C. A., Quart. Rev. Chem. Soc., 1, 144 (1947).

‘ Long, L. H., and Norrish, R. G. W., Nature, 15 ${ }^{\circ}, 486$ (1946).

${ }^{5}$ See the discussion to the paper by Norrish, R. G. W., Trans. Farad. Soc., 30,103 (1934).

' Van Vleck, J. H., J. Chem. Phys., 2, 20, 297 (1934).

${ }^{7}$ Mulliken, R. S., J. Chem. Phys., 2, 782 (1934).

${ }^{8}$ Ufford, C. W., Phys. Rev, ii, 53, 568 (1938).

- Shenstone, A. G., Phys. Rev., ii, 72, 411 (1947).

${ }^{10}$ Springall, H. D., Trans. Farad. Soc., 43, 177 (1947).

${ }^{11}$ Butler, E. T., and Polanyi, M., Trans. Farad. Soc., 39, 19 (1943).

${ }^{12} \mathrm{See}$ for example, the discussions and references given by Walsh, A. D., Trans. Farad. Soc., 43, 60 (1947); J. Chem. Soc., 398 (1948).

\section{GERMAN MOTOR ROADS}

$\mathrm{B}$ EFORE the War much interest was taken in Great Britain in the German Autobahnen. Their design and construction were well described then in both the technical and popular press. The system is the only modern road network planned on a national scale and is worthy of most careful study in order that practice in Britain and elsewhere may profit as much as possible from German experience. The recent B.I.O.S. Overall Report*, entitled "German Motor Roads, 1946", is therefore particularly valuable in that it gives comprehensive information on the present state of these roads. The report, which contains thirty-nine excellent plates, is clearly and succinctly written and can be strongly recommended to the general reader.

* British Intelligence Objectives Sub-committee Overall Report No. 5. (H.M. Stationery Office, 1948.) 18 . $6 d$. net.
The roads have been laid out on new ground, independently of existing roads, so as to link the main cities and industrial areas. The great extent of the system is emphasized by the fact that although a length of some 2,380 miles of dual-carriageway road is already in service, only about one half of the length originally planned has been completed. One of the chief impressions gained by the observers was of the high quality maintained throughout rather than of any exceptional excellence in particular sections, which were nowhere better than has been achieved elsewhere. This consistency is attributed to the policy of working to a single standard determined centrally, and of employing contractors carefully selected for their ability to undertake work of such a magnitude. The designs of the later roads were modified in the light of the experience gained from those already in service.

An admirable feature is the absence of extensive cracking of the concrete surfaces; this has been achieved by building on a gravel foundation, the material being imported if it was not already available locally. The elaborate plans adopted at crossings and road junctions to avoid the conflict of traffic lanes are well known; when adequately signposted, these are not found to be confusing. Another striking feature is the design of bridges; a great variety of construction has been used to suit local conditions and the workmanship is described as being of outstanding merit. Fifteen photographs in the report give a good idea of the lightness of effect achieved in over-bridges and of the pleasing design of the underbridges ; the latter carry the roads across valleys and are often larger than are met with in common practice owing to the stringent gradient restrictions which were maintained. Care has also been taken to blend the roads into the landscape by careful location, by rounding the slopes of cuttings and embankments, and by the method of planting adopted.

The report finally concludes that "the lay-out and alignment of the German motor roads are of a suffi. ciently high standard to suggest a degree of safety and sense of security above that obtained on ordinary main roads in Britain". Undoubtedly we can learn much not only from the felicities of this great experiment but also from its defects, a number of which are recorded and illustrated. R. H. MACMILLAN

\section{CONSTITUTION OF THE PLANETS}

MORE than thirty pages of the first part for this N year of the Monthly Notices of the Royal Astronomical Society are devoted to "Reports on the Progress of Astronomy", under which is included "The Constitution of the Planets", "Solar Activity", "Comets" and "Double Stars". By far the longest of these is the first, and it is possible to glance at only a few of the points dealt with by Rupert Wildt.

Quite recently our view that satellites could not retain atmospheres has been shown to be incorrect, as methane absorption has been discovered in the spectrum of Titan. The atmosphere of Titan, which is stable under present conditions, would have its stability endangered if its temperature were raised by only $100^{\circ} \mathrm{C}$. Hence, if the evolution of the satellite passed through a stage of high surface temperature-as is believed to have happened with all the members of the solar system-the atmosphere 